\title{
Experience in the design and operation of retaining walls of overpasses of the Central Ring Road on the base with soil improvement by vibro stone columns
}

\author{
Sergey Rytov $^{{ }^{*}}{ }^{*}$, Ilya Iovlev ${ }^{1}$, and Tatyana Rytova $^{2}$ \\ ${ }^{1}$ NIIOSP named after N.M. Gersevanov JSC Research Center of Construction, 109428, 59, building \\ 1, Ryazansky prospekt, Moscow, Russia \\ ${ }^{2}$ Moscow State University of Civil Engineering, Yaroslavskoe shosse, 26, Moscow, 129337, Russia
}

\begin{abstract}
Reinforced retaining walls were used on the overpasses of the Central Ring Road. To reduce the sedimentation of the base of these walls, to reduce the time of consolidation of the base, the transformation of soil properties by reinforcing vibro stone columns was used. In order to obtain an optimal result for the transformation of the properties of the base soils, increasing the reliability of the reinforced structures, comparative calculations were carried out with the variation of the parameters of the reinforcing elements. The method of quality control of the device vibro stone columns is improved.
\end{abstract}

\section{Introduction}

A promising method of strengthening weak soils when creating artificial structures is the transformation of the properties of the base with reinforcing vibro stone columns. This method is relevant in the design of highways [1-3]. For example, the use of mechanically stabilized earth walls (MSE-walls) allows you to reduce the width of the right-of-way and eliminate the need to transfer existing communications and roadside infrastructure.

As the practice of operation of these MSE-walls shows, during construction and operation, deformations caused by uneven precipitation of the base are possible. Reducing the deformability of the base allows you to increase the reliability of MSE-walls.

The regulatory documents do not cover in sufficient detail the issue of the maximum values of the deformations of the base for MSE-walls, only the possible mechanisms of destruction are considered. So, for example, in the ODM 218.2.027-2012, the requirements for the deviation of the front surface of the MSE-walls are given, but there is no tolerance for the maximum precipitation of the base.

To obtain an optimal result for the transformation of the properties of the base soils, to increase the reliability of the MSE-walls, comparative calculations were carried out with the variation of the step of the reinforcing elements and the modulus of deformations of the

*Corresponding author: lab38@niiosp.ru 
vibro stone columns, on the basis of the calculations performed, the modulus of deformation of the transformed soil was obtained.

The novelty of this article is to improve the methods of calculating the base of MSEwalls and methods of quality control of the work performed. The results of field tests are presented in articles [4-6]. Field tests with a $3 \times 3 \mathrm{~m}$ stamp provide an integral estimate of the modulus of deformation of the transformed soil, but they are more time-consuming and require the installation of an anchor fastening system. In this regard, it required the development of less time-consuming control methods, taking into account previous studies [7-16].

\section{Materials and methods}

\subsection{Geological conditions of the construction site}

MSE-walls were used on the overpasses of the Central Ring Road. To reduce the settlement of the base of these walls, the soil improvement by reinforcing vibro stone columns with a diameter of $600 \mathrm{~mm}$ was used. To develop optimal solutions for strengthening the foundation, pre-design work and a series of field tests were carried out, followed by an examination of the deformations of the erected structures on the example of the PK 490 site.

The construction sites of the Central Ring Road (SKAD) overpasses are characterized by the presence of highly compressible soils. A fragment of the plan diagram of the Central Ring road is shown in Figure 1.

A characteristic geological section for the MSE-wall at the support No. 2 PK $490+49.61$ SKAD is shown in Figure 2.

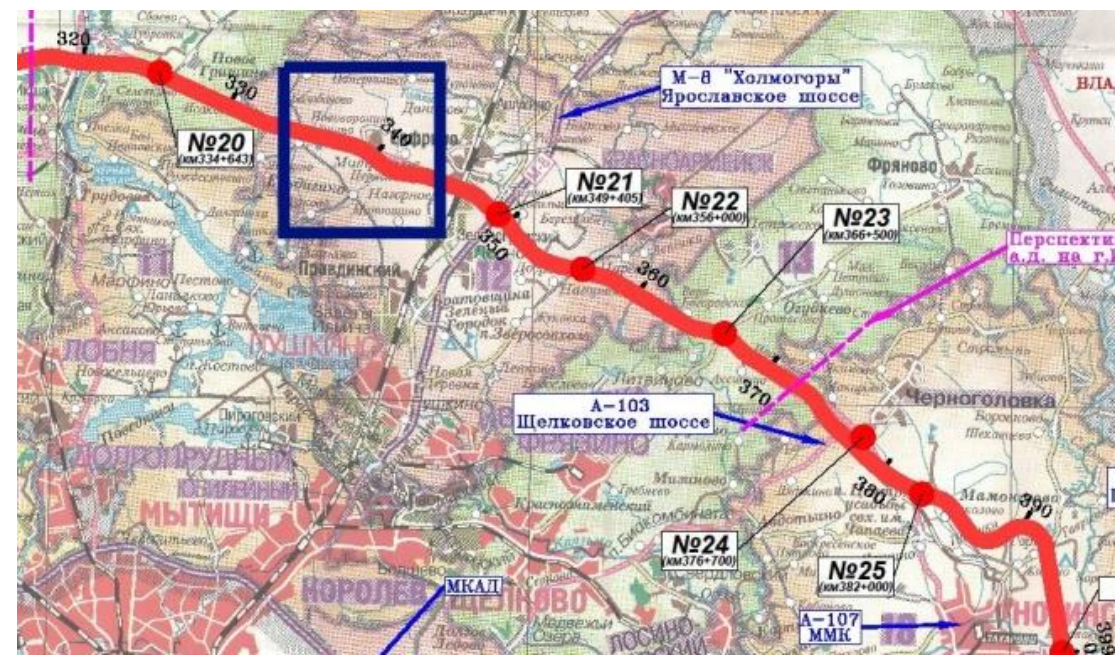

Fig. 1. A fragment of the plan of the Central Ring Road (the position of PC 490 is shown by a rectangle). 


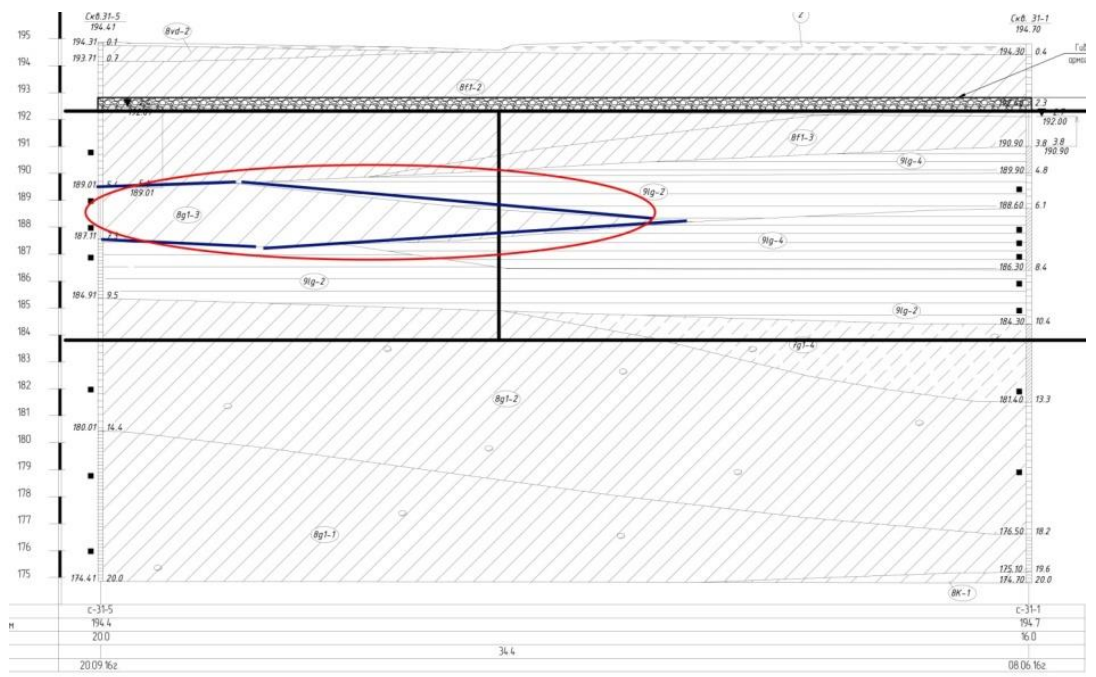

Fig. 2. A characteristic geological section on the example of the MSE-wall at the support No. 2 PK $490+49.61 \mathrm{SKAD}$ (the zone of weak soils is circled by an ellipse).

The geological conditions of the site belong to the II category of complexity [17]. At the base of the MSE-wall of the overpass is located soil № 8g1-3 with a deformation modulus $\mathrm{E}=7 \mathrm{MPa}$ (in Figure 2, highlighted by an ellipse).

\subsection{Design features of the designed structures}

When developing design solutions for overpasses, several options were worked out. One of the options provided for the use of MSE-walls to reduce the number of spans. The option with MSE-walls is shown in Figure 3.

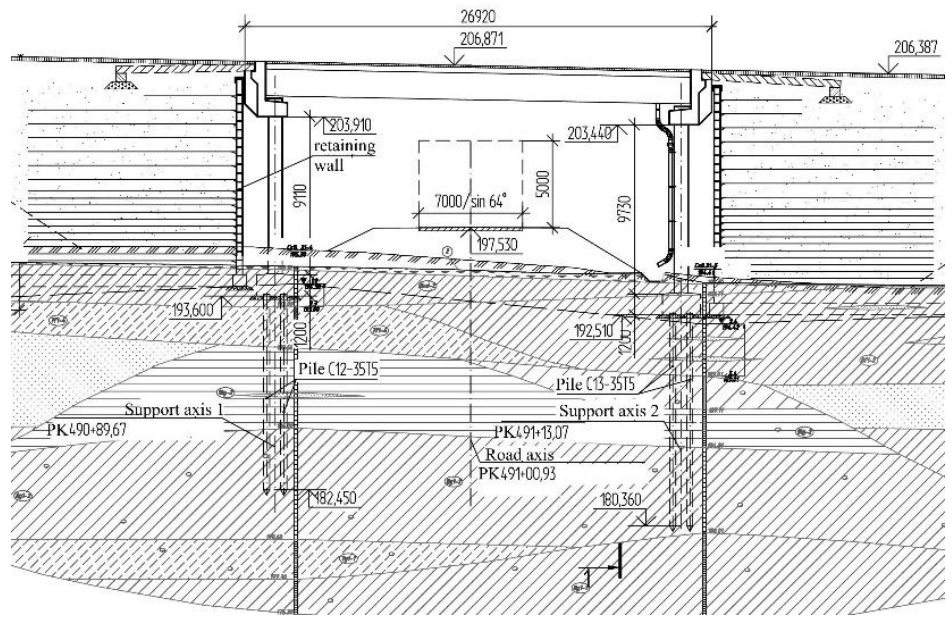

Fig. 3. Version of the overpass with the use of MSE-walls.

The general designer has previously assessed the settlement of the base of the MSEwalls and concluded that it is necessary to strengthen the foundation soil. At the same time, 
the calculated draft of the base of the right side of wall (in two calculated software systems) was $220 \mathrm{~mm}$, the left side-up to $50 \mathrm{~mm}$ (Fig. 4) taking into account $[18,19]$.

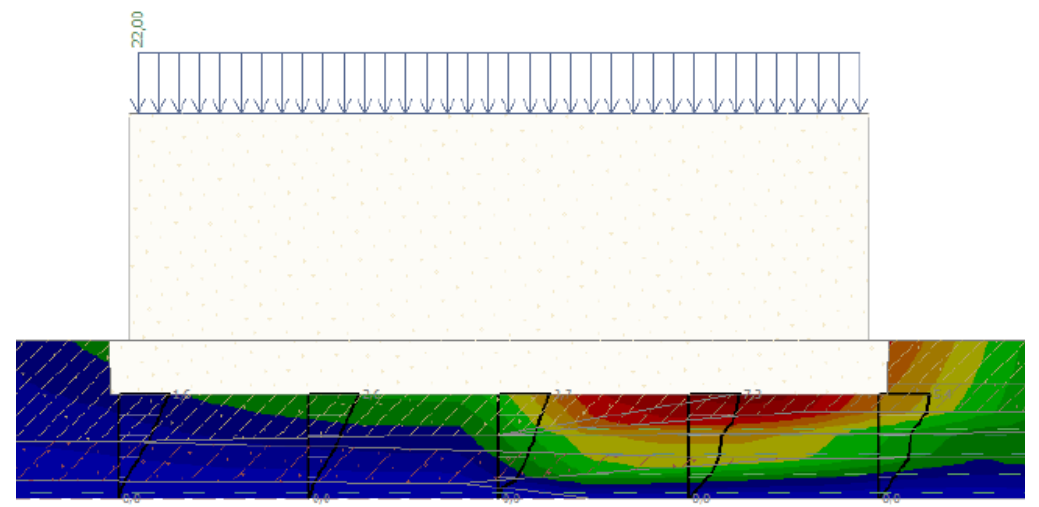

Fig. 4. Precipitation of the base of the MSE-wall (the draft on the right is $220 \mathrm{~mm}$, on the left-50 $\mathrm{mm})$.

Together with the NIIOSP, several options were considered for reducing the base settlement (replacing weak soil, soil improvement with vibro stone columns).

The option of partial replacement of the soil led to a decrease in the calculated precipitation, but did not meet the regulatory criteria, so the option with the use of vibro stone columns with a diameter of $600 \mathrm{~mm}$ was worked out in more detail [20].

To reduce the uneven settlement of the base, a different grid for vibro stone columns was used $(1.2 \times 1.2 \mathrm{~m}$ and $1.8 \times 1.8 \mathrm{~m}$ with a length of $8.5 \mathrm{~m})$. At the same time, the deformation modulus for vibro stone columns was assumed to be $\mathrm{E}=50 \mathrm{MPa}$. For the grid $1.2 \times 1.2 \mathrm{~m}$, the preliminary modulus of deformations of the transformed soil was $27 \mathrm{MPa}$, for the grid 1.8x1.8 m-24 MPa.

To confirm the design decisions made, a series of field tests was performed, including SPT and stamp tests according to GOST 20276-2012. A fragment of the plan of vibro stone columns for a MSE-wall is shown in Figure 5.

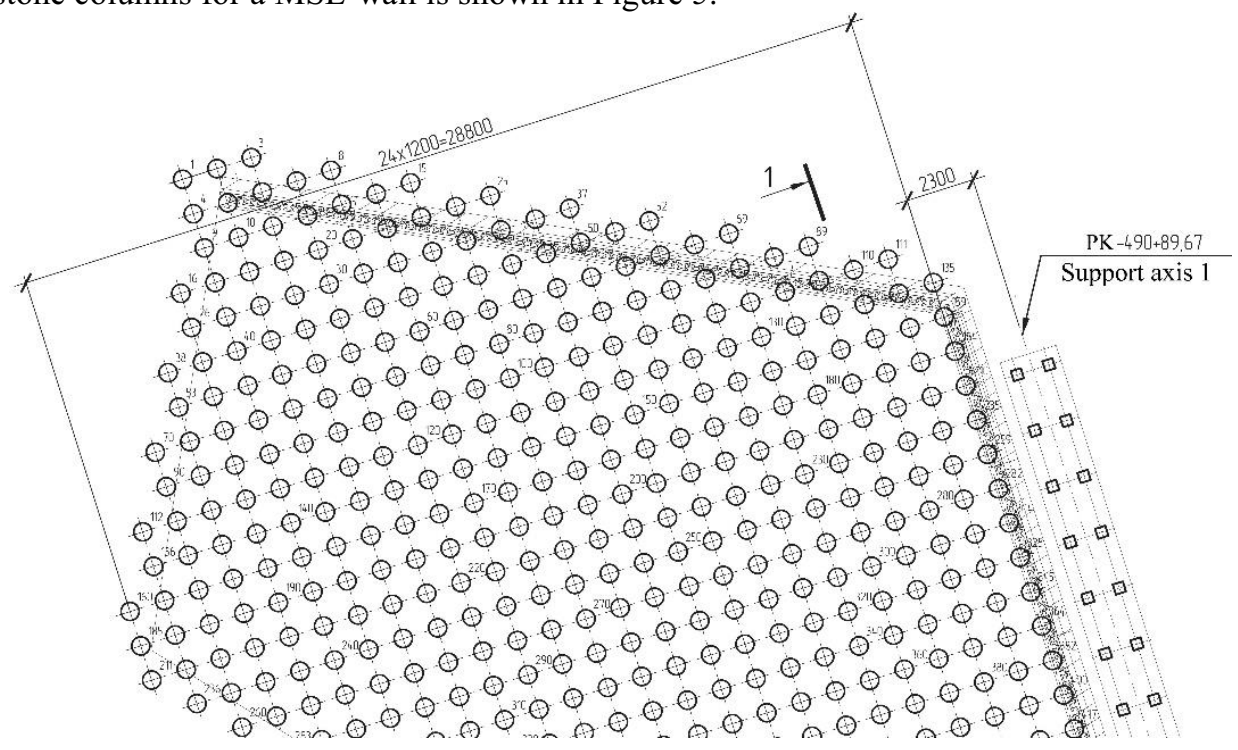

Fig. 5. A fragment of the plan of vibro stone columns under the MSE-wall. 
The technological scheme of installation of vibro stone columns is shown in Figure 6.
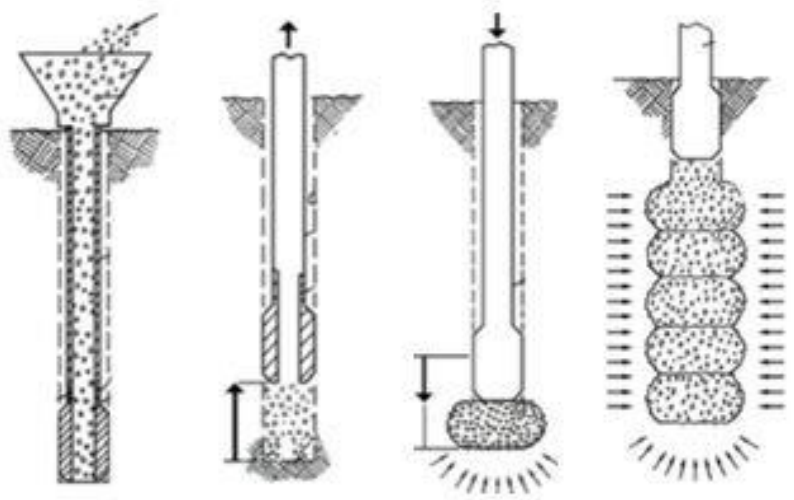

Fig. 6. The technological scheme of installation of vibro stone columns:

1 - well construction by immersion of ramming equipment with a lost tip; 2 - crushed stone feed into the well with phased extraction of ramming equipment; 3 - compaction of the bottom of vibro stone columns by ramming crushed stone; 4 - layer-by-layer compaction of crushed stone

General view of the equipment for installation of vibro stone columns is shown in Figure 7.

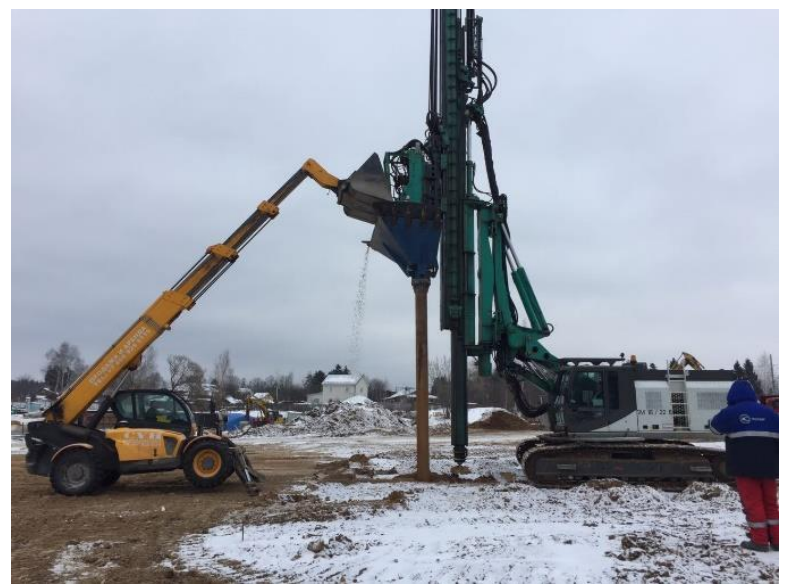

Fig. 7. General view of the equipment for installation of vibro stone columns.

Previously, field tests were carried out with stamps measuring $3 \times 3 \mathrm{~m}$ [4-6]. Such tests provide a more reliable estimate of the modulus of deformations of the transformed soil, but they are more time-consuming and require the installation of an anchor system (Figure 8).

In this regard, there was a need to improve the control methods, which involved performing SPT and stamp tests to determine the deformation modulus of the vibro stone columns itself for subsequent recalculation of the reduced deformation modulus of the reinforced base (Fig. 9). 


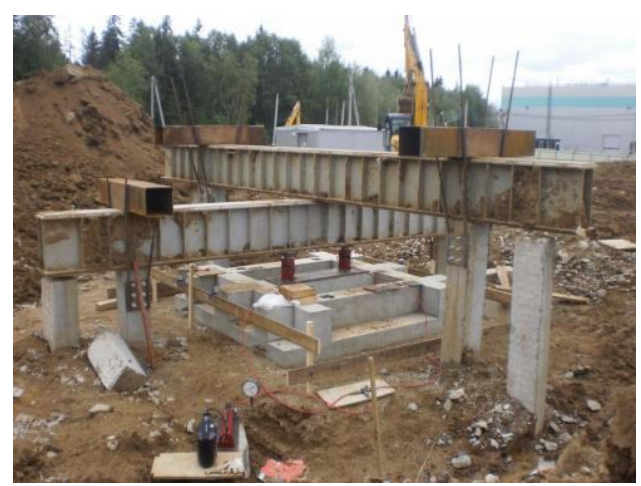

Fig.8. Stamp tests for determining the modulus of deformations of the transformed soil

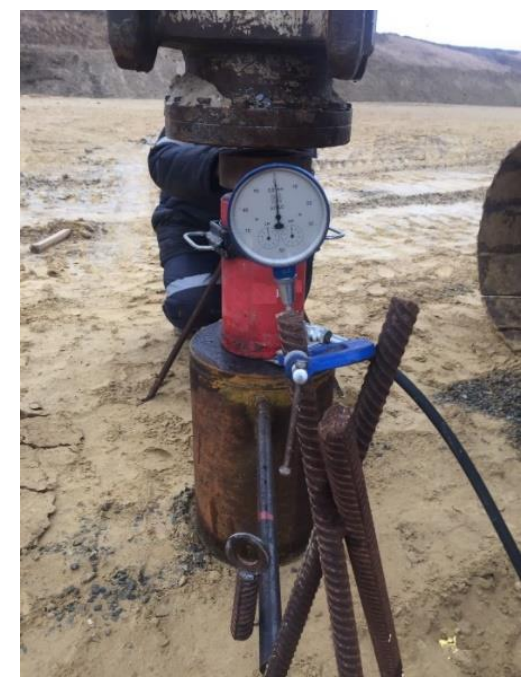

Fig. 9. Die tests for determining the deformation modulus of a vibro stone columns

\section{Results}

According to the results of stamp tests (Fig. 9), verification calculations were carried out in a flat formulation by the finite element method to assess the stabilized settlement of the base of the MSE-wall, taking into account with soil improvement. The calculated model took into account not discrete elements, but the reduced modulus of deformation for each geological element. According to the results of calculations, the maximum settlement was 9 $\mathrm{cm}$ during the construction of the embankment, $10 \mathrm{~cm}$ during additional loading with a temporary load taking into account $[4,5]$.

The accepted permissible settlement according to SP 22.13330 .2016 is $20 \mathrm{~cm}$. The criterion of the maximum uneven settlement was adopted by $1 / 100$ of the height of the structure $-12 \mathrm{~cm}$.

The predicted settlement did not exceed the permissible values, taking into account soil improvement with vibro stone columns. The working documentation provided for monitoring of settlement of the base of the MSE-wall during construction and the first year of operation (observations were not carried out). Part of the work on the construction of the retaining wall was carried out in the winter.

The implemented version of the MSE-wall is shown in Figure 10. 


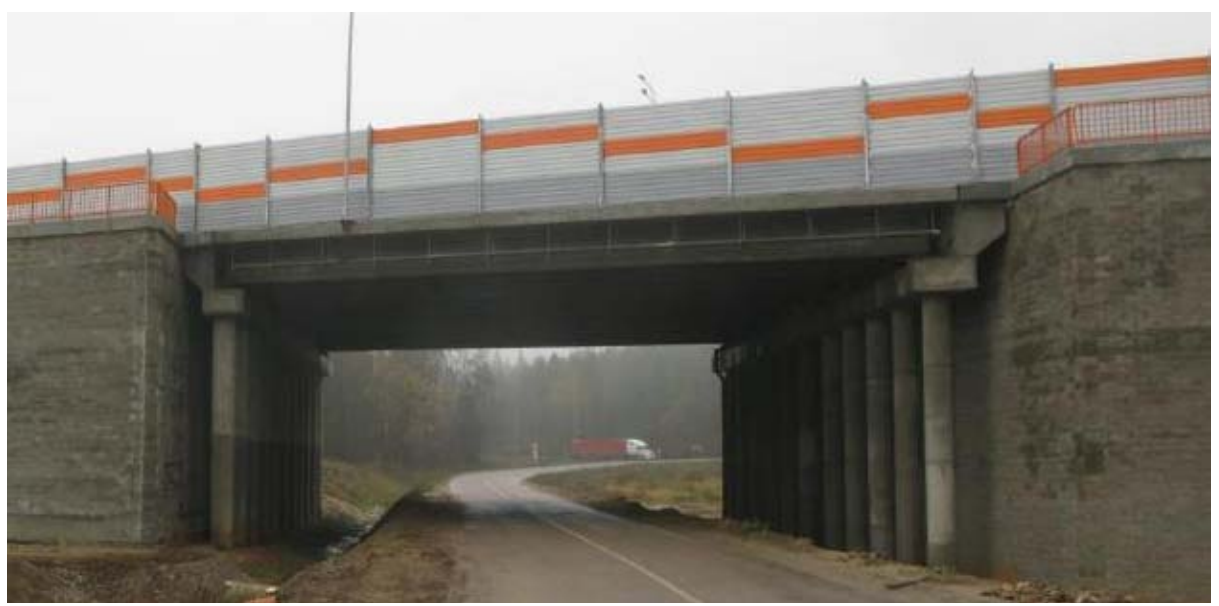

Fig. 10. Implemented version of the MSE-wall

During the first year of operation in MSE-wall was revealed the following defects: the offset from the horizontal rows facing walls, cracks in blocks up to 5-6 mm (Fig. 11), chipped corners, partial precipitation of rubble drainage through the gaps formed to $15 \mathrm{~mm}$.

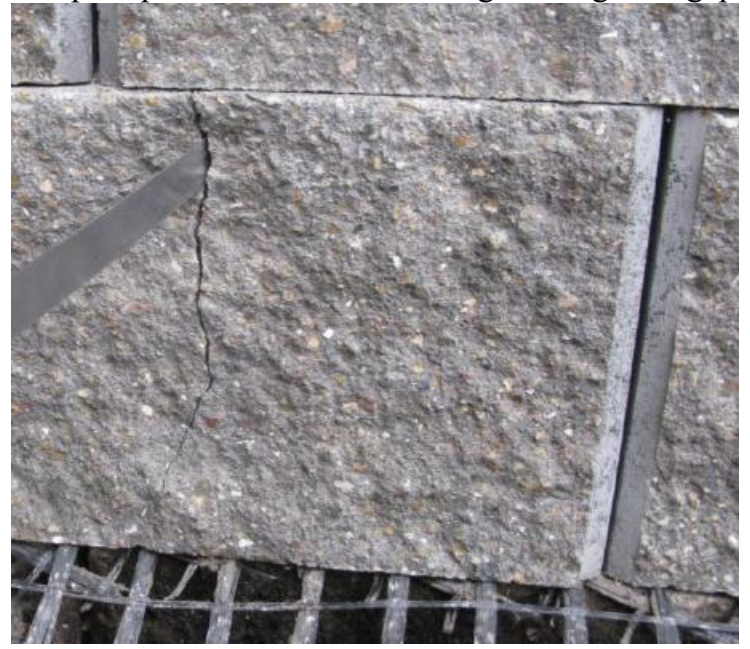

Fig. 11. Fragment of the MSE-wall lining with a defect

\section{Conclusions}

The implemented version of the overpass with a reduced number of spans due to the use of MSE-walls made it possible to simplify its design scheme, reduce the cost of construction and installation work, and increase reliability.

The soil improvement with vibro stone columns allowed to reduce the estimated settlement of the MSE-wall, to reduce the time of soil consolidation at its base. Field tests were conducted in accordance with GOST 20276-2012 to confirm the design decisions made.

It is mandatory to monitor the precipitation of the base of the MSE-wall during construction and in the first year of operation to compare the estimated and actual 
settlement. A possible cause of the identified defects is the use of frozen non-cohesive soil when performing the MSE-wall itself.

In case of defects in the cladding and to exclude the possibility of collapse of its individual elements, it was necessary to strengthen the facade and side walls, as well as to seal the gaps between the individual blocks.

\section{References}

1. E. S. Aspis, Monitoring operated subgrade, the theoretical foundations and practical solutions (MIIT, 2002)

2. A. N. Kostousov, Improving the methodology for calculating armogrunt walls for strengthening the earthwork (MIIT, 2015)

3. L. I. Semendyaev, Automobile roads, 12, 12-19 (1998)

4. S. A. Rytov, T. G. Rytova, Possible measures to reduce uneven deformation of floor structures of warehouse complexes in FORM-2020. IOP Conf. Series: Materials Science and Engineering 869, 052044 (2020)

5. S. A. Rytov, The experience of transforming the building properties of soils in civil and road construction, in Geotechnics in Belarus: science and practice: proceedings of the International Conference, 23-26 October 2018, Minsk, BNTU, 336-342 (2018)

6. S. A. Rytov, I. F. Valiev, Bulletin of the SRC Construction, 2 (17), 101-108 (2018)

7. T. M. Allen, R. J. Bathurst, Washington State Transportation Center, WARD-522.2 (2003)

8. R. J. Bathurst, N. Vlachopoulos, D. L. Walters, P. G. Burgess, T. M. Allen, Canadian Geotechnical Journal, 43(12), 1225-1237 (2006)

9. R. Berg, B. R. Christopher, N. Samtani, FHWA-NHI-10-024/025 (2009)

10. Y. M. Cheng, T. Lansivaara, W. B. Wei, Computers and Geotechnics, 34, 137-150 (2007)

11. M. Ehrlich, L. D. Becker, Reinforced soil wall measurements and predictions, in Conf. on Geosynthetics: Geosynthetics for a challenging world, IGS Brasil and ABMS, 1, 547- 559 (2010)

12. B. Huang, R. J. Bathurst, K. Hatami, T. M. Allen, Canadian Geotechnical J., 47(8), 885-904 (2010)

13. S. W. Jacobsz, J. of the South Africa Institute of Civil Engineering, 55(1), 85-93 (2013)

14. D. Leshchinsky, F. Tatsuoka, Geosynthetics Magazine, 31(3), 12-21 (2013)

15. S.B.A. Mohamed, K-H Yang,W-Y Hung, Computers and Geotechnics, 61, 67-84 (2014)

16. R. J. Valentine, An Assessment of the Factors that Contribute to the Poor Performance of Geosynthetic-Reinforced Earth Retaining Walls, in Proceedings of the International Symposium on Design and Practice of Geosynthetic-Reinforced Soil Structures, 14-16 October, 2013, Bologna, Italy, DEStech Publications, 751, 318-330 (2013)

17. Technical report on the results of geological surveys. Construction of the Central Ring Road of the Moscow Region, 3, Cipher: 171-PIR-IG-1.3.4.4.4/IPS-344-16-IGI1. 3.4.4.4. (2016)

18. U. Smoltczyk, Geotechnical engineering handbook (Wiley, 2, 2003)

19. A. Z. Ter-Martirosyan, Interaction of the foundations of buildings and structures with a water-saturated base when taking into account the nonlinear and rheological properties of soils (MGSU, 2016)

20. Working documentation. The Central ring road of the Moscow Region. Overpass on PK 490+49.61. 48. Code: 171-80 / 16-IS. 48-11-2-PS2 (2017) 